Journal of Current and Advance Medical Research

January 2018, Vol. 5, No. 1, pp. 33-38

http://www.banglajol.info/index.php/JCAMR

ISSN (Print) 2313-447X

ISSN (Online) 2413-323X

DOI: http://dx.doi.org/10.3329/jcamr.v5i1.36544

ORIGINAL ARTICLE

OPEN@ACCESS

\title{
Blood Glucose Level in Low Birth Weight Babies in First 48 Hours of Life
}

\author{
Md. Khairuzzaman ${ }^{1}$, Nihar Ranjan Sarker ${ }^{2}$, Mst. Monjuman Ara Sarker ${ }^{3}$, Abdul Matin $^{4}$, \\ Sudesh Chandra Rakshit ${ }^{5}$, Bikash Mojumder ${ }^{6}$, Md. Nurul Absar ${ }^{7}$
}

\begin{abstract}
${ }^{1}$ Assistant professor (Neonatology), Department of Pediatrics, Shaheed Suhrawardy Medical College, Dhaka, Bangladesh; ${ }^{2}$ Associate Professor, Department of Pediatrics, Shaheed Suhrawardy Medical College, Dhaka, Bangladesh; ${ }^{3}$ Junior Consultant (Gynaecology \& Obstetrics), Dhamrai Health Complex, Dhamrai, Dhaka, Bangladesh; ${ }^{4}$ Associate Professor, Department of Pediatrics, Shaheed Suhrawardy Medical College, Dhaka, Bangladesh; ${ }^{5}$ Assistant Professor, Department of Pediatrics, Shaheed Suhrawardy Medical College, Dhaka, Bangladesh; ${ }^{6}$ Associate Professor, Department of Pediatrics, Rangpur Medical College, Rangpur, Bangladesh; ${ }^{7}$ Professor, Department of Pediatrics, Rangpur Medical College, Rangpur, Bangladesh
\end{abstract}

[Reviewed: 3 October 2017; Accepted on: 10 December 2017; Published on: 1 January 2018]

\section{Abstract}

Background: Transient hypoglycemia in the early neonatal period is a common adaptive phenomenon as the newborn changes from the fetal state of continuous transplacental glucose consumption to intermittent nutrient supply following cessation of maternal nutrition at birth. This adaptation is well established in term appropriate for gestational age babies but is not established in low birth weight babies. Objective: this study was undertaken to evaluate glycemic status of the low birth weight babies and impact of early feeding. Methodology: This prospective observational study was done in the department of Pediatrics and department of obstetrics, Rangpur Medical College Hospital, Rangpur, Bangladesh from September 2005 to February 2006 for a period of six (6) months. Blood sugar was estimated at birth (cord blood) and then from capillary blood at 2 hours, 4 hours, in between 12 to 24 hours and in between 24 to 48 hours. The capillary blood was obtained by heel prick. Venous sample was sent to the college laboratory for confirmation if the blood sugar was less than $2.6 \mathrm{mmol} / \mathrm{L}(47 \mathrm{mg} / \mathrm{dL})$. Result: In the first 48 hours, the blood glucose levels were lowest at 2 hours after delivery and the level gradually increased with increasing postnatal age in low birth weight babies. Birth weight had a positive correlation with blood glucose levels of low birth weight babies. The overall incidence of hypoglycemia in low birth weight babies were $31.8 \%$, among them $77.1 \%$ asymptomatic and $22.9 \%$ symptomatic. The mean blood glucose levels were significantly high in early feed group than the delayed feed group babies $(\mathrm{p}<0.05)$. Conclusion: The blood glucose levels is lowest at 2 hours after delivery and the level gradually increases with increasing postnatal age in low birth weight babies which is a positive correlation with blood glucose levels of low birth weight babies. [Journal of Current and Advance Medical Research 2018;5(1):33-38]

Keywords: Low birth weight; blood glucose level; hypoglycemia

Correspondence: Dr. Md. Khairuzzaman, Assistant Professor (Neonatology), Department of Paediatrics, Shaheed Suhrawardy Medical College, Dhaka, Bangladesh; Email: lipton.zaman@gmail.com; cell no.: +8801714537243

Cite this article as: Khairuzzaman M, Sarker NR, Sarker MMA, Matin A, Rakshit SC, Mojumder B, Absar NM. Blood Glucose Level in Low Birth Weight Babies in First 48 Hours of Life. J Curr Adv Med Res 2018;5(1):33-38

Funding: No funding agency.

Conflict of Interest: All the authors have declared that there was no conflict of interest.

Contributions to authors: Khairuzzaman M, Sarker NR, Sarker MMA, Matin A RH have contributed in protocol preparation upto the report writing; furthermore; Rakshit SC, Mojumder B, Absar NM have written \& revised the manuscript.

Copyright: (92018. Khairuzzaman et al. Published by Journal of Current and Advance Medical Research. This article is published under the Creative Commons CC BY-NC License (https://creativecommons.org/licenses/by-nc/4.0/). This license permits use, distribution and reproduction in any medium, provided the original work is properly cited, and is not used for commercial purposes. 


\section{Introduction}

One of the most metabolic problems encountered in neonates is hypoglycemia. Generally, neonatal hypoglycemia is not a medical condition, but a manifestation of the newborn's ability to adapt from the fetal state of continuous transplacental glucose consumption to the extrauterine pattern of intermittent nutrient supply ${ }^{1}$. With the abrupt cessation of maternal nutrition at birth, transient neonatal hypoglycemia in the first 2 to 4 postnatal hours is almost always universal ${ }^{2}$.

The maintenance of normoglycemia in newborns depends upon adequacy of glycogen stores, maturation of glycogenolytic and gluconeogenic pathways and an integrated endocrine response ${ }^{3}$. In the term healthy newborn, this dynamic process is self-limiting and is not considered pathologic as the term neonate has the unique capacity to sustain normoglycemia and achieve successful metabolic adaptation, even in a fasting state, via the breakdown and mobilization of endogenous glycogen in the liver and kidney, hepatic synthesis of glucose from other substrates and production of alternative cerebral fuels such as ketone bodies through fatty acid mobilization $^{3-5}$. Infants born prematurely or following intrauterine malnutrition may develop abnormally low plasma glucose concentration for a prolonged period as a result of failure to adapt a metabolic and endocrine response ${ }^{1,6}$.

The overall prevalence depends on birth weight, gestational age and intrauterine growth retardation. One Malaysian study showed that hypoglycemia was seen $34.2 \%$ in small for gestational age (SGA) and $27.1 \%$ in appropriate for gestational age (AGA) infants ${ }^{7}$. More than $95 \%$ of low birth weight (LBW) babies are born in developing countries. In Bangladesh about 30 percent of infants are born with low birth weight ${ }^{8}$.

Glucose is an essential nutrient for the brain. Abnormally low levels (hypoglycemia) can cause encephalopathy and have the potential to produce long-term neurological sequel. The level at which this potential for long term injury is reached is controversial $^{9-10}$. The increased incidence of LBW makes such studies vital to formulation of recommendation for prevention and treatment within 48 hours of life to reduce neonatal mortality rate $^{3}$. A huge number of LBW babies born in Bangladesh. In With this background, this preset study was undertaken to evaluate glycemic status of the low birth weight babies and impact of early feeding.

\section{Methodology}

This prospective observational study was done in the department of Pediatrics and department of obstetrics, Rangpur Medical College Hospital, Rangpur from September 2005 to February 2006. The study protocol was approved by the Review Board of Bangladesh College of Physician \& Surgeon and ethical clearance was obtained from the institution ethical board. All term and preterm healthy low birth weight newborns delivered during the study period were included at birth. Low birth weight babies with any illness, LBW babies born to diabetic mother, maternal tocolytic therapy with beta-sympathomimetic agents and thiazide diuretics, LBW babies born with sepsis risk factor, babies need NICU admission and receiving intravenous fluid were excluded from the study. During the study period, a total of 163 newborns were enrolled according to inclusion criteria. Each baby was screened for exclusion criteria. Informed consent was taken from the parents of the babies included in the study. Babies were selected prospectively using a random number table. A detailed history was taken and through clinical examination was done in each case and information's were recorded in a questionnaire. Septicemias, hypothermia, perinatal asphyxia that may affect the glycemic status as well as features of hypoglycemia were cautiously excluded from history and clinical examination in subsequent follow up. Gestational assessment was done by the New Ballard Score. Weights of the infants were taken using baby weighing scale machine graduated from 0 to $20 \mathrm{~kg}$ with the capacity to measure $1 / 20^{\text {th }}$ of kilogram.

The newborn was classified depending on gestational age and birth weight as follows term intrauterine growth retardation (IUGR), preterm appropriate for gestational age (AGA) and Preterm IUGR according to Battagli and Lubchenco percentile chart. After enrollment of the newborn, with all aseptic precaution blood samples were taken from cord (as basal) at birth and then from capillary blood at 2 hours, 4 hours, in between 12-24 hours and in between 24-48 hours. The capillary blood was obtained by heel prick. The cord and capillary blood glucose were measured by using "Accu-ChekActive"-glucometer using the details of the procedure as mentioned by the manufacturer. Venous sample was sent to the college laboratory for confirmation if the blood sugar was less than 2.6 $\mathrm{mmol} / \mathrm{l}(47 \mathrm{mg} / \mathrm{dl})$. A blood glucose level less than $2.6 \mathrm{mmol} / \mathrm{l}$ irrespective of age, gestational age and birth weight was considered as hypoglycemia. Symptoms of hypoglycemia if associated were recorded. Infants were considered as asymptomatic 
hypoglycemia if low blood glucose level $(<2.6$ $\mathrm{mmol} / \mathrm{l}$ ) was not associated with clinical signs. Neonates with hypoglycemia were managed as per the standard protocol. All infants were started breast feeding or expressed breast milk as soon as possible as per hospital policy (based on baby friendly hospital policy). Maintenance feeding was given 2 hourly with direct breast feeding or expressed breast milk by cup and spoon or NG tube if the baby cannot suck adequately. Based on baby friendly hospital initiative, all newborns were stayed with mother and skin to skin contact was practiced to encourage breast feeding. Newborns were separated from mother only in cases of maternal illness and until she is transferred to the word. Formula feeds were given only if mother remains unavailable beyond 2 hours or if breast milk was not adequate as the study population was high risk group to develop hypoglycemia. Time of onset of breast feeding was recorded in each case. Early feeding is defined as initiation of feeding within 1 hour of delivery and "delayed feeding" as initiation of feeding beyond 1 hour of delivery. No prelacteal feeding feeds were given. Blood glucose levels were analyzed with regard to distribution, variations with age, mode of delivery, birth weight, time of initiation of first feeding, IUGR vs AGA, preterm IUGR vs term IUGR, and frequency of hypoglycemia with or without symptoms at different sampling times. Unpaired Students ' $t$ ' test and repeated analysis of variance were applied where necessary for statistical analysis using the SPSS (12.0 version) statistical package.

\section{Result}

A total of 163 low birth weight babies were included as study group according to the inclusion criteria. Twelve newborns were dropped out due to incomplete follow up, developed early onset septicemia in subsequent follow up and parents having no interest to continue the study. Finally 151 newborns were completed the study and final analysis included these newborns. Out of 151 newborns, 64(42.4\%) were term IUGR, 16(10.6\%) were preterm IUGR and 71(47.0\%) were preterm AGA.

The mean \pm SD of birth weight and gestational age was $1780 \pm 269.7$ gram and $36.09 \pm 5.47$ weeks respectively in the study population. The mean \pm SD of blood glucose levels in study population were $4.05 \pm 0.61 \mathrm{mmol} / \mathrm{L}$ at birth (cord), 2.31 \pm 0.34 $\mathrm{mmol} / \mathrm{L}$ at 2 hours, $2.95 \pm 0.36 \mathrm{mmol} / \mathrm{L}$ at 4 hours, $3.13 \pm 0.50 \mathrm{mmol} / \mathrm{L}$ at $12-24$ hours and $3.42 \pm 0.57$ $\mathrm{mmol} / \mathrm{L}$ at $24-48$ hours of age after birth. Repeated analysis of variance showed significant difference between blood glucose levels at birth, 2 hours, 4 hours, 12-24 hours and 24-48 hours of age $(\mathrm{p}=0.005)$ (Table 1).

Table 1: Mean \pm SD blood glucose levels $(\mathrm{mmol} / \mathrm{l})$ in study population at different sampling time

\begin{tabular}{|l|c|}
\hline Age (hours) & $\begin{array}{l}\text { Mean } \pm \text { SD of blood glucose } \\
\text { level }(\mathbf{m m o l} / \mathrm{L})\end{array}$ \\
\hline At birth & $4.05 \pm 0.61$ \\
\hline $2 \mathrm{~h}$ & $2.31 \pm 0.34$ \\
\hline $4 \mathrm{~h}$ & $2.95 \pm 0.36$ \\
\hline 12 to $24 \mathrm{~h}$ & $3.13 \pm 0.50$ \\
\hline 24 to $48 \mathrm{~h}$ & $3.42 \pm 0.57$ \\
\hline
\end{tabular}

In the first 48 hours, the lowest blood glucose levels were found at 2 hours after delivery and the level gradually increased with increasing postnatal age (Figure 1).

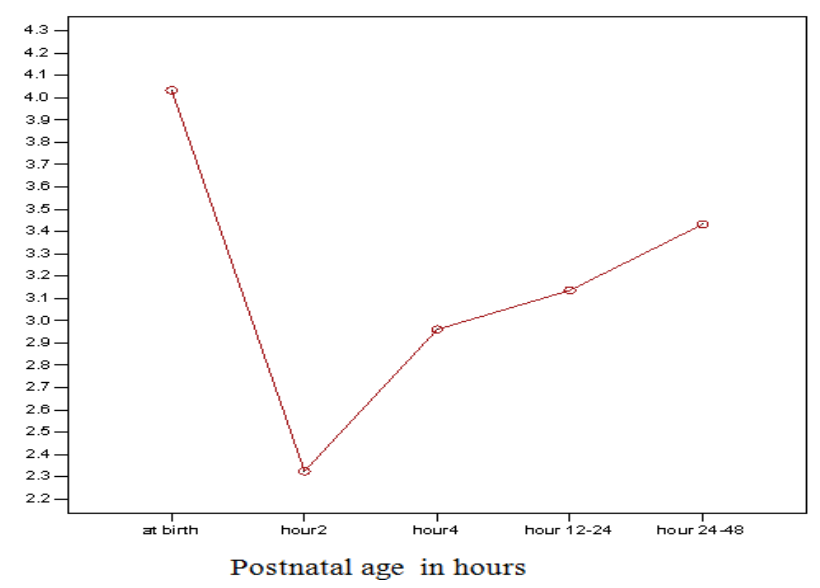

Figure 1: Line diagram showing blood glucose level in the study population in first 48 hours of life according to sampling time (The $Y$ axis indictes the mean blood glucose level ( $\mathrm{mmol} / \mathrm{L})$

There was statistically significant difference in blood glucose levels of LBW babies with variation of birth weight at $2(\mathrm{p}=0.04)$ and $4(\mathrm{p}=0.04)$ hours of age (Table 2).

Table 2: Blood glucose $(\mathrm{mmol} / \mathrm{L})$ distribution according to birth weight (Mean \pm SD)

\begin{tabular}{|c|c|c|c|}
\hline \multirow{2}{*}{$\begin{array}{l}\text { Different } \\
\text { Sampling } \\
\text { Time }\end{array}$} & \multicolumn{2}{|c|}{ Birth Weight } & \multirow[t]{2}{*}{$P$ value } \\
\hline & $<1.8 \mathrm{~kg}$ & $\geq 1.8 \mathrm{~kg}$ & \\
\hline At birth & $4.12 \pm 0.32$ & $3.99 \pm 0.53$ & 0.75 \\
\hline $2 \mathrm{~h}$ & $2.20 \pm 0.25$ & $2.43 \pm 0.29$ & 0.04 \\
\hline $4 \mathrm{~h}$ & $2.54 \pm 0.21$ & $3.34 \pm 0.26$ & 0.04 \\
\hline 12 to $24 \mathrm{~h}$ & $3.1 \pm 0.28$ & $3.2 \pm 0.30$ & 0.12 \\
\hline 24 to $48 \mathrm{~h}$ & $3.50 \pm 0.72$ & $3.52 \pm 0.45$ & 0.65 \\
\hline
\end{tabular}

$\mathrm{P}$ value reached by Student's ' $\mathrm{t}$ ' test 
Among the $151 \mathrm{LBW}$ babies, 48(31.8\%) infants had low blood glucose $(<2.6 \mathrm{mmol} / \mathrm{L})$ levels. Out of 48 infants, 32 cases had hypoglycemia at 2 hours, 9 cases had hypoglycemia at 4 hours and 7 cases had hypoglycemia at 12 to 24 hours. Hypoglycemia was not found at birth and at 24 to 48 hours of age (Table $3)$.

Table 3: Frequency of hypoglycemia at different sampling times $(\mathbf{n}=151)$

\begin{tabular}{|c|c|c|}
\hline \multirow{2}{*}{$\begin{array}{l}\text { Time of } \\
\text { sampling }\end{array}$} & \multicolumn{2}{|c|}{ Blood Glucose $(\mathrm{mmol} / \mathrm{L})$} \\
\hline & $<2.6$ & $\geq 2.6$ \\
\hline At birth & $0(0 \%)$ & $151(100 \%)$ \\
\hline $2 \mathrm{~h}$ & $32(21.1 \%)$ & $119(78.9 \%)$ \\
\hline $4 \mathrm{~h}$ & $9(5.9 \%)$ & $142(94.1 \%)$ \\
\hline 12 to $24 \mathrm{~h}$ & $7(4.6 \%)$ & $144(95.4 \%)$ \\
\hline 24 to $48 \mathrm{~h}$ & $0(0 \%)$ & $151(100 \%)$ \\
\hline
\end{tabular}

Among the 48 hypoglycemic LBW babies, $37(77.1 \%)$ babies were asymptomatic and $11(22.9 \%)$ were symptomatic. There was no significant difference in blood glucose levels of symptomatic and asymptomatic babies ( $>0.05$ ) (Table 4). Hypoglycemia was found in $50.0 \%$ of preterm IUGR, $35.9 \%$ of term IUGR and $23.9 \%$ of preterm AGA infants. There was no significant difference in blood glucose levels of hypoglycemic preterm IUGR, term IUGR and preterm AGA infants (Table 5).

Table 4: Distribution of hypoglycemia $(<2.6$ $\mathrm{mmol} / \mathrm{L}$ ) with or without symptoms among the study population $(n=48)$

\begin{tabular}{|l|c|c|}
\hline Type of Hypoglycemia & Frequency & Percent \\
\hline Asymptomatic & 37 & 77.1 \\
\hline Symptomatic & 11 & 22.9 \\
\hline
\end{tabular}

Mean \pm SD of blood glucose levels were not significantly different in IUGR vs AGA low birth babies but there was significant difference in blood glucose levels of preterm IUGR vs term IUGR low birth weight babies $(\mathrm{p}=0.04)$ at 2 hours of delivery (Table 6).

Table 5: Distribution of hypoglycemia $(<2.6$ $\mathrm{mmol} / \mathrm{L}$ ) among preterm IUGR, term IUGR and preterm AGA in the study population $(n=99)$

\begin{tabular}{|l|c|c|}
$\begin{array}{l}\text { Type of } \\
\text { Hypoglycemia }\end{array}$ & $\begin{array}{l}\text { Frequency of } \\
\text { hypoglycemia } \\
\text { (\%) }\end{array}$ & $\begin{array}{l}\text { Blood } \\
\text { Glucose } \\
\text { (mm01/l) }\end{array}$ \\
\hline Preterm IUGR & $8(50.0 \%)$ & $1.92 \pm 0.18$ \\
\hline Term IUGR & $23(35.9 \%)$ & $2.26 \pm 0.16$ \\
\hline Preterm AGA & $17(23.9 \%)$ & $2.17 \pm 0.18$ \\
\hline
\end{tabular}

Statistical test was done by repeated analysis of variance; $p$ value $=0.42$

Table 6 Comparison of blood glucose ( $\mathrm{mmol} / \mathrm{l})$ in IUGR vs AGA and preterm IUGR vs term IUGR in the study population (Mean \pm SD)

\begin{tabular}{|c|c|c|c|c|c|}
\hline \multirow[t]{2}{*}{ Variables (n) } & \multicolumn{5}{|c|}{ Blood Glucose Levels ( $\mathbf{m m 0 1 / / ) ~ i n ~ D i f f e r e n t ~ S a m p l i n g ~ T i m e ~}$} \\
\hline & At birth & $2 \mathbf{h}$ & $4 \mathrm{~h}$ & 12-24 h & 24-48 h \\
\hline IUGR (80) & $3.93 \pm 0.63$ & $2.26 \pm 0.24$ & $2.94 \pm 0.37$ & $3.05 \pm 0.44$ & $3.47 \pm 0.52$ \\
\hline AGA (71) & $4.05 \pm 0.60$ & $2.42 \pm 0.40$ & $2.93 \pm 0.47$ & $3.20 \pm 0.63$ & $3.60 \pm 0.46$ \\
\hline$P$ value & 0.50 & 0.09 & $\mathbf{0 . 8 0}$ & 0.29 & 0.74 \\
\hline Preterm IUGR(16) & $3.99 \pm 0.26$ & $2.12 \pm 0.20$ & $2.87 \pm 0.46$ & $3.24 \pm 0.26$ & $3.36 \pm 0.38$ \\
\hline Term IUGR (64) & $3.87 \pm 0.72$ & $2.26 \pm 0.36$ & $2.96 \pm 0.36$ & $2.96 \pm 0.46$ & $3.46 \pm 0.56$ \\
\hline$P$ value & 0.75 & 0.04 & 0.74 & 0.13 & 0.59 \\
\hline
\end{tabular}

Statistical analysis was done by unpaired t test

The mean \pm SD of blood glucose levels were significantly high in early feed group babies than the delayed feed group $(\mathrm{p}<0.05)$ (Table 7).

Table 7: Comparison of blood glucose $(\mathrm{mmol} / \mathrm{l})$ in early and delayed feeding group in the study population (Mean \pm SD)

\begin{tabular}{|l|l|c|}
\hline Groups (n) & Blood Glucose & P value \\
\hline Early feed (68) & $2.4 \pm 0.16$ & $<0.05$ \\
\hline Delayed feed (83) & $2.08 \pm 0.16$ & \\
\hline
\end{tabular}

$P$ value was reached by unpaired $t$ test

\section{Discussion}

At birth, with the sudden discontinuation of the nutrient and other supplies from the mother, the neonate mounts adaptive responses including mobilization of glucose and fatty acids from glycogen and triglyceride depots to meet the energy 
demands. All these responses are well established in term neonates who are appropriate size for gestation. But infants born prematurely or following intrauterine malnutrition may develop abnormally low plasma glucose concentration for prolonged period as a result of the failure to mount an appropriate and adequate counter regulatory metabolic and endocrine response ${ }^{1}$.There is a controversy over the definition of a "safe" blood glucose concentration, that is a value below which there is risk of long term neurodevelopmental impairment.

This study showed that the mean blood glucose levels $(2.31 \mathrm{mmol} / \mathrm{l})$ were significantly lower at 2 hours after delivery than any other point of first 48 hours of age and then the blood glucose levels gradually increased to reach normal levels with increasing postnatal age which is well correlated with the findings of Srinivasan et $\mathrm{al}^{11}$. Srinivasan et $\mathrm{al}^{11}$ showed that there was a decline in plasma glucose levels during the first 2 hours of postnatal life followed by a rise, reaching a steady-state glucose concentration by 2-3 hours after birth. Sharma et $\mathrm{al}^{12}$ also found that mean blood glucose levels in term SGA neonates was lowest at 2 hours and then uniform increased in blood sugar levels from 2 hours onward which was also consistent with present study findings. In our study, there was statistically significant difference in blood glucose levels of LBW babies with variation of birth weight at $2(p=0.04)$ and $4(p=0.04)$ hours of age.

In the present study, overall incidence of hypoglycemia was $31.8 \%$ which was lower than the study conducted by Anderson et al $(50 \%$; cut of value $<2.6 \mathrm{mmol} / \mathrm{l})^{13}$; it may be due to small sample in the present study. In our study, out of 48 hypoglycemic LBW infants, 32 had hypoglycemia at 2 hours but only 16 of those had hypoglycemic level continued in the 4 and 12-24 hours of age and require treatment. A nearly similar observation was made by Tanzer ${ }^{14}$ in the full term newborn. He found lowest blood glucose in the first 3 hours of life \& out of 12 hypoglycemic infants, only 3 infants continue hypoglycemia after 3 hours. In this study, among the hypoglycemic infants, $77.1 \%$ babies were asymptomatic and $22.9 \%$ were symptomatic. This findings was similar with the findings noted by Beard and Cornblath ${ }^{15}$. There was no significant difference in blood glucose levels of symptomatic and asymptomatic babies in the present study ( $p>0.05)$. In this study, hypoglycemia was most common in preterm IUGR group (50\%) than the term IUGR (35.9\%) and preterm AGA (23.9\%). It may be due to immaturity of glycogenolytic and gluconeogenesis enzymes along with lack of glycogen store, associated hyperinsulinism and delayed onset of feeding.

This present study showed no significant difference in blood glucose levels of hypoglycemic preterm IUGR, term IUGR and preterm AGA infants. In the present study, the mean blood glucose levels in preterm IUGR babies were significantly low than that of the term IUGR babies $(p=0.04)$ at 2 hours of delivery but no significant difference in blood glucose levels of IUGR and AGA infants. Lubchencho et $\mathrm{al}^{16}$ also showed that preterm IUGR had a significantly lower mean blood glucose level in the first few postnatal hours than the term IUGR $(p<0.05)$. The mean \pm SD of blood glucose levels were significantly high in early feed group babies than the delayed feed group and early feeding influenced the subsequent blood glucose levels $(p<0.05)$. Beard et $\mathrm{al}^{15}$ showed that early feeding of premature newborn infants prevented hypoglycemia and influenced subsequent blood glucose levels. This study findings were also well correlated with the findings of a cross sectional study of 1546 term infants and 62 preterm infants by Hawdon and Ward ${ }^{17}$. So early feeding is an important determinant of blood glucose level in low birth weight babies.

\section{Conclusion}

In the first 48 hours, the blood glucose levels were lowest at 2 hours after delivery and the level gradually increased with increasing postnatal age in low birth weight babies. Birth weight had a positive correlation with blood glucose levels of low birth weight babies in first 48 hours of age in this study. Asymptomatic hypoglycemia was more common than the symptomatic hypoglycemia among the hypoglycemic infants. Hypoglycemia was more common among the preterm IUGR babies as compared to the term IUGR and preterm AGA infants in the study population. The mean blood glucose levels were significantly high in early feed group babies than the delayed feed group and early feeding influenced the subsequent blood glucose levels.

\section{References}

1. Cornblath M, Hawdon JM, Williams AF, Aynsley-Green A, Ward-Platt MP, Schwartz R. Controversies regarding definition of neonatal hypoglycemia: suggested operational thresholds. Pediatrics 2000; 105: 1141-5

2. Hawdon JM, Ward-Platt MP, Aynsley-Green A. Prevention and management of neonatal hypoglycemia. Arch Dis Child Fetal Neonatal Ed 1994; 70: 60-4

3. World Health Organization. Hypoglycemia of the newborn: review of the literature, Geneva: WHO, 1997. 
4. Haninger NC, Farley CL. Screening for hypoglycemia in healthy term neonates: effects on breastfeeding. Journal of Midwifery and Women's Health 2001; 46: 292-301

5 . Britton JR. The transition to extrauterine life and disorders of transition. Clin Perinatol 1998; 25: 271-94.

6. McGowan JE. Neonatal Hypoglycemia: Fifty years later, the questions remain the same. American Academy of Pediatrics 2004; 5: 1-3

7. J Ho, Ling LN, Yogeswary S, Mathews V. Mortality and morbidity of small for gestational age (SGA), Very Low birth weight (VLBW) Malaysian Infant. Singapore Medical Journal 2001; 42: 355-9

8. United Nations Children's Fund and World Health Organization, Low Birth Weight: Country, regional and global estimates. New York: United Nations Children's Fund and World Health Organization; 2004: 01-12

9. Cornblath M, Schwartz R. Disorders of carbohydrate metabolism in infancy. Pediatrics 1966; 41: 789-92.

10. Inder T. How long can I go? The impact of hypoglycemia on the immature brain. Pediatrics 2008; 122: 440-1.
11. Srinivasan G, Voora S. Clinical and laboratory observationsplasma glucose values in normal neonates: a new look. The journal of pediatrics 1986; 109: 114-22

12. Sharma U, Gemawat N, Saxena S, Sharma MI. A longitudinal study of blood sugar levels in the newborns. Indian Pediatrics 1979; $16: 121-30$

13. Anderson S, Shakya KN, Shrestha I N de L, Costello AM. Hypoglycemia: A common problem among uncomplicated newborn infants in Nepal. J Trop Pediatr 1993; 39: 273-7

14. Tanzer F. Blood glucose levels and hypoglycemia in full term neonates during the first 48 hours of life. Journal of Tropical Pediatrics 1997; 43: 58-60

15. Beard A, Cornblath M. Neonatal hypoglycemia: a discussion. Journal of pediatrics 1986; 79: 314-16

16. Lubchencho LO, Bard H. Incidence of hypoglycemia in newborn infants classified by birth weight and gestational age. Pediatrics 1971; 47: 431-8.

17. Hawdon JM, Ward PMP, Aynsley GA. Patterns of metabolic adaptation for preterm and term infants in the first neonatal week. Rchives of Disease in Childhood 1992; 67: 357-65 